\title{
Intensive lifestyle intervention has little effect on cardiovascular complications in people with type 2 diabetes
}

\author{
BM Frier \\ Honorary Professor of Diabetes, The Queen's Medical Research Institute, University of Edinburgh, UK
}

TITLE Cardiovascular effects of intensive lifestyle intervention in type 2 diabetes

AUTHORS The Look AHEAD Research Group et al.

\author{
Correspondence to \\ Professor BM Frier, \\ British Heart Foundation Centre \\ for Cardiovascular Science \\ The Queen's Medical \\ Research Institute, \\ University of Edinburgh, \\ Edinburgh EHI 6 4TJ, UK
}

e-mail brian.frier@ed.ac.uk

\section{SUMMARY}

Most people with type 2 diabetes in westernised societies are overweight or obese. Lifestyle changes in the form of dietary weight reduction and exercise are usually recommended as initial treatment, before commencing glucose-lowering medications. These have been shown to provide effective diabetes management in the short-term but are difficult to maintain, while the long-term benefits of lifestyle measures to protect against cardiovascular disease (the main cause of death in type 2 diabetes) were unknown.

The Look AHEAD (Action for Health in Diabetes) study was performed in 16 centres in the USA to ascertain whether intensive lifestyle intervention would reduce cardiovascular morbidity and mortality in obese adults (mean body mass index [BMI] $36 \mathrm{~kg} / \mathrm{m}^{2}$ ) with type 2 diabetes, aged $45-75$, on various therapies including insulin. An intervention group of 2,570 participants was allocated to intensive treatment - a calorie-restricted diet $(\mathrm{I}, 200-1,800 \mathrm{kcal} /$ day $)$ and weekly exercise of moderate intensity, while a matched control group of 2,575 people received education about diet and exercise and social support in the form of (infrequent) group sessions. The primary outcome was the first occurrence of a composite of death from cardiovascular causes, non-fatal myocardial infarction or stroke and hospital admission for angina. The trial was stopped prematurely when the median follow-up was 9.6 years following a futility analysis, which showed that despite greater weight loss, decline in glycated haemoglobin ( $\mathrm{HbAlc}$ ), and improvements in physical fitness and almost all cardiovascular risk factors in the intervention group, the intensive lifestyle changes had not reduced the rate of cardiovascular events.

\section{CLINICAL OPINION}

The lack of an obvious benefit on cardiovascular outcomes after a decade of intensive lifestyle intervention is disappointing and may at first sight suggest that lifestyle changes in the management of type 2 diabetes are a waste of time. However, the short-term benefit of such measures is beyond doubt, delaying progression in the severity of diabetes, and in some people even inducing regression of glucose intolerance. ${ }^{1,2}$ In the Look AHEAD trial, positive benefits of intensive lifestyle intervention included partial remission of diabetes during the first four years, lower usage of insulin and statins, and reduced rates of urinary incontinence, sleep apnoea and depression (reported elsewhere), along with improved physical function, mobility and quality of life. Successful weight reduction was maintained at the end of the study and glycaemic control was better, although $\mathrm{HbAlc}$, blood pressure and lipid profiles were good in both groups at baseline, which may have minimised the long-term benefits of lifestyle changes. A number of studies have suggested that people with type 2 diabetes who have an elevated BMI have lower mortality than people of normal weight. This intriguing observation, known as the 'obesity paradox', has been observed in other chronic diseases such as chronic heart failure and coronary heart disease, and has prompted a debate as to whether it exists in type 2 diabetes. ${ }^{3,4}$ The negative outcome of the Look AHEAD trial could suggest that overweight people with type 2 diabetes have a survival advantage. If this is a real clinical phenomenon it would question the importance of weight loss in the management of type 2 diabetes and whether weight loss interventions will reduce mortality in type 2 diabetes.

\section{REFERENCES}

I Diabetes Prevention Program Research Group. Reduction in the incidence of type 2 diabetes with lifestyle intervention or metformin. N Engl J Med 2002; 346:393-403.

2 Tuomilehto J, Lindström J, Eriksson JG et al. Prevention of type 2 diabetes mellitus by changes in lifestyle among subjects with impaired glucose tolerance. N Engl J Med 200 I; 344: I343-50.

3 Dixon JB, Lambert GW. The obesity paradox - a reality that requires explanation and clinical interpretation. Atherosclerosis 20I3; 226:47-8.

4 Carnethon MR, DeChavez PJ, Briggs ML et al.Association of weight status with mortality in adults with incident diabetes. JAMA 2012; 308:58I-90. 